\title{
Viabilidad del uso de harina de residuos pesqueros de la Ciénaga de Zapatosa en la alimentación de pollos de engorde
}

\section{Feasibility of the use of fish waste flour in the Cíenaga de Zapatosa, for feeding of broilers}

\author{
Latife del Rosario Lúquez-Pérezi ; José Igor Hleap-Zapata²
}

1'Ing. Agroindustrial, M.Sc. Ciencias Agrarias. Universidad Nacional de Colombia, Facultad de Ciencias Agrarias. Palmira - Valle del Cauca, Colombia; e-mail: Irluquezp@unal.edu.co; (D) https://orcid.org/0000-0002-2705-1532

Ing. Pesquero, Ph.D. Ingeniería de Alimentos. Universidad Nacional de Colombia, Facultad de Ingeniería y Administración. Palmira - Valle del Cauca, Colombia; e-mail: jihleapz@unal.edu.co; (D) https://orcid.org/0000-0001-9692-5443

Cómo citar: Lúquez-Pérez, L. del R.; Hleap-Zapata, J.I. 2020. Viabilidad del uso de harina de residuos pesqueros de la Ciénaga de Zapatosa en la alimentación de pollos de engorde. Rev. U.D.C.A Act. \& Div. Cient. 23(2):e1202. http://doi.org/10.31910/rudca.v23. n2.2020.1202

Artículo de acceso abierto publicado por Revista U.D.C.A Actualidad \& Divulgación Científica, bajo una licencia Creative Commons CC BY-NC 4.0

Publicación oficial de la Universidad de Ciencias Aplicadas y Ambientales U.D.C.A, Institución de Educación Superior Acreditada de Alta Calidad por el Ministerio de Educación Nacional.

Recibido: Abril 10 de 2019 Aceptado: Diciembre 2 de 2020 Editado por: Ingeborg Zenner de Polanía

\section{RESUMEN}

La explotación pesquera, con fines de comercialización y consumo en la Cíenaga de Zapatosa, Cesar, Colombia, genera residuos representados en vísceras y otros subproductos. Se estudió la posibilidad de aprovechamiento de dichas vísceras, para la producción de harina, con fines de alimentación animal. A los subproductos de las seis especies de mayor importancia en la Ciénaga de Zapatosa, se les determinó su composición proximal y se procedió a elaborar la respectiva harina, utilizando una mezcla de las mismas, en proporciones iguales. El producto final fue evaluado, mediante parámetros bromatológicos, microbiológicos y de estabilidad. La harina se elaboró, a través de los procedimientos de cocción, prensado, centrifugación, para la eliminación de grasa y humedad, secado, molienda, empaque y almacenamiento. Los resultados mostraron un alto valor nutricional estable durante el tiempo de medición, lo que la convierte en una opción proteica favorable, para la elaboración de piensos para alimentación animal, debido a su digestibilidad del $80 \%$, su contenido de proteína del
$54 \%$, su aporte en ácidos grasos esenciales eicosapentaenoico (EPA), docosapentaenoico (DPA), docosahexaenoico (DHA) y su aporte en aminoácidos esenciales. La harina fue evaluada en la elaboración de alimentos concentrados para alimentación in vivo de pollos de engorde y se incluyó en las dietas, en comparación con piensos comerciales. El resultado mostró un mejor rendimiento productivo, representado en mejor ganancia de peso diario y mejor índice de conversión alimenticia. Se concluyó, que la harina de vísceras de pescado evaluadas son una alternativa importante para la alimentación de pollos de engorde.

Palabras clave: Harina de vísceras de pescado; Nutrición animal; Piensos para animales; Subproductos pesqueros.

\section{ABSTRACT}

Fishing exploitation, for the purpose of marketing and consumption in the Cíenaga de Zapatosa, Cesar, Colombia, generates a large amount of waste represented in viscera and other by-products. 
The possibility of using these viscera for the production of flour for animal feed was studied. For the by-products from the six most important fish species in the Cíenaga de Zapatosa, their proximal composition was determined, and the respective flour, using a mixture in equal proportions elaborated evaluated. The final product was evaluated through bromatological, microbiological and stability parameters. The flour was elaborated through the procedures of cooking, pressing, centrifugation for the elimination of fat and humidity, draying, grinding, packaging and storage. The results showed a stable nutritional value during the measurement time, which makes it a favorable protein option for the production of animal feed, due to its digestibility of $80 \%$, its protein content of $54 \%$, its contribution in essential fatty acids eicosapentaenoic (EPA), docosapentaenoic (DPA), docosahexaenoic (DHA) and its contribution in essential amino acids. This flour was evaluated in the preparation of concentrated feeds for in vivo feeding of broilers, compared with commercial feed. The result showed a better productive performance represented in better daily weight gain and better feed conversion index. The results allow to conclude that the meal of fish viscera of the six most commercially important species obtained in the Cíenaga de Zapatosa, are an important alternative for feeding broilers.

Keywords: Fish visceral meal; Animal nutrition; Feed for animals; Fishing by-products.

\section{INTRODUCCIÓN}

La pesca, gracias a su interés alimenticio y comercial, se ha posicionado como una de las actividades de mayor importancia para el ser humano. En Colombia, se cuenta con una gran diversidad de peces y un consumo per cápita, de $8,00 \mathrm{~kg} /$ persona/año (AUNAP, 2018). La Ciénaga de Zapatosa, ubicada en el norte del país, entre los departamentos de Cesar y Magdalena, presenta una sobreexplotación de recursos pesqueros, lo que ha afectado la seguridad alimentaria de la región (Viloria, 2008). Dicha sobreexplotación acarrea una mayor producción de residuos pesqueros, los cuales, por considerarse recursos de poco valor comercial, generalmente, son vertidos a las aguas de la Ciénaga, en los sitios de comercialización, sin ningún tipo de tratamiento. Lo anterior, además de afectar el medio ambiente y los ecosistemas naturales, genera malos olores, producción de metabolitos y toxinas dañinas para la población, aumento de la carga orgánica y de microorganismos patógenos, provocando eutrofización, lo que conlleva a una disminución del oxígeno disponible en el agua (Malone \& Newton, 2020).

Los residuos pesqueros poseen un apreciable valor nutricional, lo que ha llevado a que, a nivel mundial, se hayan realizado estudios relacionados con el aprovechamiento de dichos recursos, siendo, la más común, su transformación en la elaboración de harinas y aceites de pescado, para uso en la fabricación de piensos, para la alimentación animal (Hodar et al. 2020; Valenzuela et al. 2012). Según Vásquez-Torres et al. (2013), las harinas de residuos de pescado son mejores que otras harinas de origen vegetal y animal, debido a su contenido de proteínas, su aporte en aminoácidos esenciales, la presencia de ácidos grasos poliinsaturados y su digestibilidad.
Las harinas de vísceras de pescado, se han utilizado como fuente de proteína para la alimentación de diferentes especies animales. Perea-Román et al. (2018) presentan un trabajo, en el cual, utilizaron los residuos de la producción de trucha (Onkorbynchus mykiss), en la elaboración de ensilados, para la alimentación de tilapia roja (Oreochromis spp.). Igualmente, Al-Marzooqui et al. (2010) utilizaron ensilado de sardina en la alimentación de pollos, mientras que Valenzuela et al. (2015), emplearon las vísceras del salmón en la alimentación de pollos broiler y Ramírez et al. (2013), trabajaron en la alimentación de codornices, empleando ensilado de vísceras de pescado y Garcés et al. (2015), alimentaron pollos, utilizando ensilado de subproductos piscícolas.

Con el fin de aprovechar el material visceral de las especies pesqueras disponibles en grandes cantidades en dicha Ciénaga y de esta forma mitigar los índices de contaminación de la misma, el objetivo del presente trabajo fue el de caracterizar y evaluar la viabilidad del aprovechamiento de los residuos de la actividad pesquera de la zona, para la elaboración de harina de vísceras de pescado (HVP), con el fin de elaborar piensos, para la alimentación de pollos de engorde.

\section{MATERIALES Y MÉTODOS}

Área de estudio. Los estudios, se realizaron en la Ciénaga de Zapatosa, localizada en territorio de los departamentos de Cesar y Magdalena, circundada por los municipios de El Banco (Magdalena), Tamalameque, Chimichagua, Curumaní, Chiriguaná (Cesar). Se ubica, según el sistema de coordenadas MAGNA-SIRGAS (Marco Geocéntrico Nacional de Referencia, densificación en Colombia del Sistema de Referencia para las Américas), entre los $9^{\circ} 0^{\prime}$ y $9^{\circ} 18^{\prime} \mathrm{N}$ y $73^{\circ} 40^{\prime}$ y $73^{\circ} 56^{\prime}$ O. La laguna, se encuentra a $42 \mathrm{~m}$ s.n.m., posee una temperatura promedio anual de $30^{\circ} \mathrm{C}$, una humedad relativa de $70 \%$ y las precipitaciones oscilan entre 1.200 y $1.800 \mathrm{~mm}$ (IDEAM, 2012).

Estimación de residuos pesqueros. Para la determinación del volumen de residuos pesqueros, se hizo un seguimiento en los diferentes puertos de desembarco. Para esto, se utilizaron datos estadísticos del volumen de desembarco, publicados en el sistema de información del Servicio Estadístico Pesquero Colombiano (SEPEC, 2018), información suministrada por los pescadores, la Autoridad Nacional de Acuicultura y Pesca seccional Cesar (AUNAP, 2014) y la Secretaría de Agricultura del Departamento del Cesar.

Muestreo. Las vísceras, se recolectaron a partir de las principales especies ícticas encontradas: Bocachico (Prochilodus magdalenae), Bagre (Pseudoplastytoma magdalenatium), Pácora (Plagioscion surinamensis), Mojarra (Caquetaia kraussii), Pincho (Cyphocharax magdalenae) y Areca (Triportheus magdalenae). Las vísceras, en una cantidad de $60 \mathrm{~kg}$ por cada especie y sitio de captura, se sometieron a un proceso manual de troceado y se distribuyeron en bandejas de aluminio, identificadas por especie y sitio de recolección. Seguidamente, se sometieron a secado, en una estufa marca Thermo Scientific ${ }^{\text {TM }}$ Precision $^{\text {TM }}$ Model 658 Oven, con control de temperatura y circulación de aire forzado, a $50^{\circ} \mathrm{C}$, durante 7 a 8 horas. Finalmente, las vísceras secas, se sometieron a molturación, en un molino universal marca IKA modelo MF 10, diseñado para funcionar entre 3.500 y 4.500rpm. 
Caracterización bromatológica y microbiológica de las vísceras. Los análisis bromatológicos, se desarrollaron de acuerdo con los métodos descritos por la Association of Official Analytical Chemists (AOAC, 2006): materia seca - método AOAC - 934.01, proteína - método AOAC - 976.05, extracto etéreo - método AOAC - 920.34, cenizas - método AOAC - 942.05, fibra cruda - método AOAC - 962.09 y la cuantificación de extracto libre de nitrógeno (ELN), por diferencia. Los análisis microbiológicos realizados fueron: Aerobios mesófilos $\mathrm{UFC} \mathrm{g}^{-1}$, Coliformes fecales $\mathrm{UFC} \mathrm{g}^{-1}$, Escherichia coli $\mathrm{UFC} \mathrm{g}^{-1}$, Esporas Clostridium Sulfito reductor UFC $\mathrm{g}^{-1}$, Salmonella en $25 \mathrm{~g}$, Estafilococo coagulasa positiva UFC $\mathrm{g}^{-1}$ y Recuento de mohos y levaduras UFC $\mathrm{g}^{-1}$. Se desarrollaron de acuerdo con las directrices técnicas de alimentos para animales y sales mineralizadas (ICA, 2014).

Elaboración de la HVP. Se elaboró, de acuerdo con el procedimiento anotado por Valenzuela et al. (2012). Para la elaboración de la HVP, las vísceras de las seis especies utilizadas, se mezclaron en proporciones iguales y se trabajó como una sola mezcla de materia prima. Las vísceras libres de descomposición, se sometieron a cocción, durante 30 minutos, con vapor de agua, en un rango de temperatura entre 95 y $100^{\circ} \mathrm{C}$, con el fin de coagular las proteínas y liberar las grasas presentes. Posteriormente, se realizó el prensado de la masa, para extraer el licor de prensa, lo cual, permitió separar el agua de cola y el aceite presente en las vísceras, obteniendo, finalmente, la torta de prensado. Para esto, el licor de prensa, se sometió a una separación de sus componentes (agua, aceite, solidos solubles e insolubles), utilizando una centrífuga marca Robatell Rousselet RA-20-VX a 2500rpm. El agua de cola, se sometió a calentamiento, para evaporar el líquido y concentrar los sólidos presentes. Todos los sólidos recuperados junto con la torta de prensa, se llevaron en bandejas de aluminio, a una estufa de secado marca Thermo Scientific ${ }^{\mathrm{TM}}$ Precision ${ }^{\mathrm{TM}}$ Model 658 Oven, a una temperatura constante de $48^{\circ} \mathrm{C}$, durante 15 a 20 horas. La masa obtenida, se dejó reposar a temperatura ambiente $\left(25-30^{\circ} \mathrm{C}\right)$ por dos horas, antes de ser sometida a molienda, la cual, permitió obtener un polvo fino y homogéneo. Finalmente, a la HVP, se le adicionó Butilhidroxitolueno - BHT, como agente antioxidante, en una concentración de $100 \mathrm{mg} / \mathrm{kg}$, atendiendo la Resolución No. 4124 de 1991 del Ministerio de Salud y Protección Social de Colombia (MINSALUD, 1991) y se procedió a almacenarla en sacos plásticos herméticos.

Determinación del valor nutricional y parámetros microbiológicos de la HVP. Para el análisis proximal de la HVP, se siguió las normas de la AOAC. Los minerales ( $\mathrm{P}, \mathrm{Fe}$ y $\mathrm{Ca}$ ), se terminaron de residuo de cenizas, mediante espectrofotometría de absorción atómica, según el método AOAC 956.17, 2009. A través de un análisis de High Performance Liquid Chromatography (HPLC), se determinó el contenido de aminoácidos, según lo propuesto por Gorostegui et al. (2012). El perfil de ácidos grasos, se determinó a través de la Técnica de cromatografía de gases, haciendo una extracción de lípidos en solución de cloroformo/metanol 2/1, de acuerdo con lo descrito por American Oil Chemists' Society (AOCS, 2017). La determinación de metales pesados ( $\mathrm{Hg}, \mathrm{Pb}$ y Cd), se realizó por espectrofotometría de absorción atómica, con un espectrofotómetro de flama marca FP8400 A. Krüss Optronic, Germany.

Se evaluó la vida útil de la harina a los 5 y a los 30 días de almacenamiento. Se determinó: a) índice de acidez, a través de la medición de los ácidos grasos libres, según el método AOAC 962.19 y se expresó como porcentaje de masa; b) índice de rancidez, mediante el índice de peróxidos con técnica volumétrica, expresado como miliequivalentes de oxígeno activo $/ \mathrm{kg}$, según el método AOAC 965.33; el ácido tiobarbitúrico, que expresa el contenido de malondialdehido determinado por extracción, destilación y cuantificación por espectrofotometría con TBA; método de absorbancia a 530 $\mathrm{nm}$ y expresado en $\mathrm{mg} / \mathrm{kg}$ y el valor de anisidina (AOCS CD 18-90) y c), bases nitrogenadas volátiles totales BNVT, a través del método de titulación, con hidróxido de sodio y expresado en $\mathrm{mg} / 100 \mathrm{~g}$. Finalmente, se realizó una prueba in vitro de digestibilidad enzimática de la materia seca, según el método propuesto por Ruiz et al. (2005).

Evaluación in vivo de la asimilación de la HVP en pollos de engorde. Las unidades experimentales, se instalaron en Valledupar (departamento de Cesar). Para esto, se confeccionaron cuatro galpones, utilizando listones de madera y malla plástica, revestidos con una cama de cisco de arroz de $15 \mathrm{~cm}$ de espesor, con criadores de bombillo 100 watts y con bebederos y comederos automáticas. Se usaron 100 pollos sin sexar, de un día de nacidos de la línea de Cobb 500. Los pollos, se dividieron en cuatro grupos de 25 unidades por tratamiento y se formularon dietas alimenticias, para cada tratamiento, con base en lo propuesto por Rostagno (2011), en las cuales, el porcentaje de inclusión de HVP fue de $\mathrm{T}_{1}(5 \%), \mathrm{T}_{2}(10 \%)$, $\mathrm{T}_{3}(15 \%)$ y $\mathrm{T}_{4}(0 \%)$ - tratamiento control), concentrado comercial, cuya composición se muestra en la tabla 1. La experimentación, se realizó por triplicado y el período de evaluación fue de seis semanas. Para estimar el efecto nutricional de la HVP en la alimentación de los pollos, se determinó: consumo de alimentos (CA), ganancia total de peso (GTP), ganancia diaria de peso (GDP), factor de conversión alimentaria (FCA) y mortalidad (MA), según lo propuesto por Alkahir et al. (2017). Los resultados, se muestran como el promedio de las tres repeticiones realizadas para cada tratamiento analizado. La digestibilidad de los alimentos suministrados, se valoró de acuerdo con la metodología propuesta por Osorio-Carmona et al. (2012). Para estimar el efecto nutricional de la HVP en la alimentación de los pollos, los ejemplares se pesaron semanalmente, registrando el peso de los mismos, así como también los pesos de los alimentos suministrados y de los alimentos sobrantes, con el fin de estimar el consumo total de alimento. En la tabla 1, se muestran las formulaciones de las dietas suministradas a los pollos y el valor nutricional de las mismas.

Análisis estadístico. La comparación de promedios, se realizó de acuerdo con la prueba de Duncan y se aceptaron diferencias significativas de $5 \%$ de probabilidad. Finalmente, para la evaluación de la HVP en pollos de engorde, se utilizó un diseño completamente al azar, en donde se evaluaron las variables consumo de alimento, ganancia total de peso, ganancia diaria de peso, índice de conversión alimenticia y mortalidad, con un nivel de confianza del 5\% y pruebas 
Tabla 1. Formulaciones de las dietas suministradas a los pollos y valor nutricional de las mismas.

\begin{tabular}{|c|c|c|c|c|c|c|c|}
\hline \multirow[b]{2}{*}{ Alimento } & \multicolumn{2}{|c|}{$\begin{array}{c}\mathrm{T}_{1} \\
(5 \% \text { HVP) }\end{array}$} & \multicolumn{2}{|c|}{$\begin{array}{c}\mathrm{T}_{2} \\
(10 \% \mathrm{HVP})\end{array}$} & \multicolumn{2}{|c|}{$\begin{array}{c}\mathrm{T}_{3} \\
(15 \% \mathrm{HVP})\end{array}$} & \multirow{2}{*}{$\begin{array}{c}\mathbf{T}_{4} * \\
(\mathbf{0} \%-\text { control }) \\
\mathrm{kg}\end{array}$} \\
\hline & $\mathrm{kg}$ & $\%$ & $\mathrm{~kg}$ & $\%$ & $\mathrm{~kg}$ & $\%$ & \\
\hline Maíz amarillo & 51,00 & 51,00 & 50,06 & 50,06 & 48,17 & 48,17 & 49,8 \\
\hline Harina de soya $48 \%$ (proteína) & 29,00 & 29,00 & 20,10 & 20,10 & 18,00 & 18,00 & 30,0 \\
\hline Aceite vegetal & 2,40 & 2,40 & 2,40 & 2,40 & 2,40 & 2,40 & 2,90 \\
\hline Sal común & 0,50 & 0,50 & 0,50 & 0,50 & 0,50 & 0,50 & 0,30 \\
\hline Pre mezcla vit-min & 0,50 & 0,50 & 0,50 & 0,50 & 0,50 & 0,50 & 0,10 \\
\hline Fosfato dicálcico & 4,00 & 4,00 & 4,00 & 4,00 & 4,00 & 4,00 & 1,52 \\
\hline Di-metionina $99 \%$ & 0,30 & 0,30 & 0,30 & 0,30 & 0,30 & 0,30 & 0,29 \\
\hline Avena & 7,17 & 7,17 & 12,01 & 12,01 & 11,00 & 11,01 & - \\
\hline Harina de yuca & - & - & - & - & - & - & 6,00 \\
\hline L-lisina $\mathrm{HCl} 78 \%$ & 0,13 & 0,13 & 0,13 & 0,13 & 0,13 & 0,13 & 0,15 \\
\hline HVP & 5,00 & 5,00 & 10,00 & 10,00 & 15.00 & 15,00 & - \\
\hline Torta de soya & - & - & - & - & - & - & 8,94 \\
\hline Total & 100,00 & 100,00 & 100,00 & 100,00 & 100,00 & 100,00 & 100,00 \\
\hline E.M. pollos $(\mathrm{Kcal} / \mathrm{Kg})$ & \multicolumn{2}{|c|}{3006,00} & \multicolumn{2}{|c|}{3028,00} & \multicolumn{2}{|c|}{3070,00} & 3220,00 \\
\hline
\end{tabular}

*Concentrado comercial.

de promedio, por el método de Duncan. Todos los datos fueron analizados usando el programa Statistical Analysis Software SAS versión 9.4 (SAS Institute Inc. USA).

\section{RESULTADOS Y DISCUSIÓN}

Estimación de los recursos pesqueros. El porcentaje de vísceras para peces de agua dulce fluctúa entre el 8 y el $12 \%$, con respecto al peso corporal de los peces (Pinzón et al. 2016). Estos datos correspondieron con los hallados en la presente investigación, en donde se corroboró un promedio de $10 \%$ de vísceras para las seis especies analizadas. Por lo anterior, del 2013 al 2018, el total del desembarco pesquero en la Ciénaga de Zapatosa fue de 4059,55 toneladas (SEPEC, 2018), pudiendo concluir que, en los últimos seis años, se han producido cerca de $400 \mathrm{~T}$ de vísceras de pescado, que podrían ser utilizadas para la alimentación animal.

Caracterización bromatológica y microbiológica de las vísceras. Los resultados del análisis proximal de las especies estudiadas, se muestran en la tabla 2. El menor valor para el extracto etéreo lo presentó el Bagre y el mayor valor se obtuvo para el Pincho, con diferencias estadísticamente significativas $(\mathrm{p}<0,05)$, entre los promedios (media para $\mathrm{n}=3$ ). En promedio, para las seis especies objeto de estudio, el contenido de grasas fue de $33,85 \%$, datos que coinciden con los reportados en otras investigaciones: $35,76 \%$, en Bocachico (Pinzón et al. 2016); 31,93, en truchas (David-Ruales et al. 2014) y 33,01\%, en tilapia (Ramírez et al. 2016). Lo anterior evidencia que los residuos pesqueros poseen un contenido adecuado de lípidos, favoreciendo, desde el punto de vista energético, su utilización en la alimentación animal. El contenido de humedad, para cada una de las especies y en promedio para las seis especies $(2,07 \%)$ fue bajo, debido a que las vísceras fueron sometidas a un secado previo, para evitar alteraciones y descomposición bacteriana. Los valores asociados a la proteína, para las diferentes especies, presentaron diferencias significativas entre ellas $(p<0,05)$, debido a la diversidad nutricional de las especies estudiadas. El valor promedio de proteína en las especies fue de $45,46 \%$. Los valores obtenidos superan los registrados por Pinzón et al. (2016), quienes trabajaron con vísceras de Bocachico $(39,88)$ y por Fonseca et al. (2020), quienes encontraron un valor de $28,00 \%$, para vísceras de tilapia nilótica (Oreochromis niloticus). El contenido de cenizas hallado fue similar al obtenido por López et al. (2006) en peces de rio y quienes, además, indicaron que dichos peces contienen sales minerales de importancia fisiológica, por su aporte de fósforo, calcio y magnesio. Las especies estudiadas mostraron diferencias significativas en cuanto al contenido de fibra $(\mathrm{p}<0,05)$, que son nutrientes disponibles en las células vegetales, pero en materias de origen animal, su contenido es muy bajo. Las trazas de fibra encontradas en las vísceras de pescado, en la presente investigación, pueden ser atribuidas a pequeñas ingestas de material vegetal de las especies, especialmente, para el Bocachico, el Pincho (especies detritivas) y la Arenca (especie omnívora). El valor obtenido para el Extracto Libre de Nitrógeno (ELN), como promedio de las vísceras de las seis especies analizadas, mostró un valor similar a lo reportado por Spanopoulos-Hernández et al. (2010), en un trabajo realizado con tilapia. Finalmente, el aporte energético, en promedio para las especies analizadas, superó lo reportado por Osorio et al. (2014), quienes trabajaron con tilapia nilótica $(274,26 \mathrm{kca} / 100 \mathrm{~g})$ y con trucha arco iris $(250,75 \mathrm{kcal} / 100 \mathrm{~g})$. 
Tabla 2. Composición proximal y análisis microbiológico de las vísceras de las principales especies ícticas de la Ciénaga de Zapatosa.

\begin{tabular}{|c|c|c|c|c|c|c|}
\hline & Bocachico & Pácora & Mojarra & Pincho & Bagre & Arenca \\
\hline \multicolumn{7}{|c|}{ Composición proximal } \\
\hline Extracto etéreo $\mathrm{g} / 100 \mathrm{~g}$ & $35,16^{\mathrm{b}}$ & $30,66^{\mathrm{c}}$ & $34,71^{\mathrm{b}}$ & $37,08^{\mathrm{a}}$ & $29,06^{\mathrm{c}}$ & $36,40^{\mathrm{a}}$ \\
\hline Humedad g/100g & $2,82^{a}$ & $1,20^{\mathrm{e}}$ & $2,53^{\mathrm{b}}$ & $2,37^{\mathrm{b}}$ & $1,54^{\mathrm{d}}$ & $2,01^{\mathrm{c}}$ \\
\hline Proteína $\mathrm{g} / 100 \mathrm{~g}$ & $40,12^{\mathrm{e}}$ & $47,70^{\mathrm{b}}$ & $47,02^{\mathrm{b}}$ & $44,66^{\mathrm{c}}$ & $49,62^{a}$ & $43,66^{\mathrm{d}}$ \\
\hline Cenizas $\mathrm{g} / 100 \mathrm{~g}$ & $15,19^{\mathrm{a}}$ & $13,80^{\mathrm{b}}$ & $11,06^{\mathrm{d}}$ & $11,24^{\mathrm{d}}$ & $12,91^{\mathrm{c}}$ & $11,55^{\mathrm{d}}$ \\
\hline $\mathrm{ELN}^{1} \mathrm{~g} / 100 \mathrm{~g}$ & $3,66^{\mathrm{b}}$ & $2,08^{\mathrm{c}}$ & $1,82^{\mathrm{c}}$ & $4,73^{\mathrm{a}}$ & $0,75^{\mathrm{d}}$ & $3,24^{\mathrm{b}}$ \\
\hline Fibra $g / 100 \mathrm{~g}$ & $3,97^{\mathrm{bc}}$ & $2,86^{\mathrm{a}}$ & $3,34^{\mathrm{b}}$ & $3,89^{\text {cd }}$ & $2,21^{\mathrm{e}}$ & $3,87^{\mathrm{d}}$ \\
\hline Valor energético Kcal/100g & $504,46^{\mathrm{d}}$ & $511,14^{\mathrm{c}}$ & $522,77^{\mathrm{b}}$ & $535,07^{\mathrm{a}}$ & $512,05^{\mathrm{c}}$ & $523,49^{\mathrm{b}}$ \\
\hline \multicolumn{7}{|c|}{ Análisis microbiológico } \\
\hline Aerobios mesófilos UFC & 1200 & 1900 & 580 & 1500 & 280 & 830 \\
\hline Coliformes totales UFC & 370 & 690 & $<10$ & 100 & $<10$ & $<10$ \\
\hline E. coli UFC & $<10$ & $<10$ & $<10$ & $<10$ & $<10$ & $<10$ \\
\hline Staphylo-coccus aureus UFC & $<100$ & $<100$ & $<100$ & $<100$ & $<100$ & $<100$ \\
\hline Mohos y levaduras UFC & $<10$ & 100 & $<10$ & $<10$ & $<10$ & $<10$ \\
\hline Clostridium sulfito reductor UFC & 40 & 100 & $<10$ & $<10$ & $<10$ & $<10$ \\
\hline Salmonella UFC & Presencia & Ausencia & Presencia & Presencia & Ausencia & Ausencia \\
\hline
\end{tabular}

${ }^{1}$ ELN (Extracto libre de nitrógeno) almidones y azúcares presentes en la muestra, se obtienen cuantitativamente por diferencia. Medias en una misma fila con diferentes superíndices difieren significativamente $(\mathrm{p}<0,05)$.

El análisis microbiológico (Tabla 2) mostró que las vísceras analizadas cumplen con los límites permisibles establecidos por la división de insumos agropecuarios del Instituto Colombiano Agropecuario ICA (2014) y por la Norma Técnica Colombiana NTC 4519, en alimentos para consumo animal. Como excepción a lo anterior, se aprecian las muestras correspondientes a Bocachico, Mojarra y Pincho, que reportaron presencia de Salmonella, debido, probablemente, a que estos animales inclinan su alimentación hacia materias orgánicas en descomposición y material contaminado del fondo de la Ciénaga. En el trabajo reportado por Herrera \& Santos (2005), sobre prevalencia de Salmonella en pescado fresco, se afirma que estas enterobacterias pueden ser incubadas en el tracto gastrointestinal de algunos peces, que se alimentan con aguas contaminadas con heces. Iguales afirmaciones hacen Ying et al. (2019), quienes analizaron la presencia de Salmonella en diferentes peces, producidos por acuicultura en China.

Valor nutricional y parámetros microbiológicos de la harina elaborada. Los resultados del análisis proximal de la HVP, se reportan en la tabla 3. No se mostraron diferencias estadísticamente significativas entre las repeticiones $(p<0,05)$. El extracto etéreo de la harina fue inferior al de las vísceras y esta diferencia se puede atribuir a que, durante el proceso de obtención de la harina, las etapas de prensado y decantación fueron repetitivas, a fin de extraer la mayor parte posible de las grasas de las vísceras, para evitar alteraciones oxidativas o rancidez. El valor encontrado (13,10\%) es relativamente alto comparado con lo presentado por Osorio et al. (2014), quienes trabajaron con harina de residuos pesqueros utilizando, únicamente, cabezas y esqueletos. Por el contrario, Embus-Clavijo (2016) indicaron que el valor de las grasas en la harina de vísceras de Tilapia fue de $40,3 \%$, por ser una harina fabricada solo con las vísceras de esta especie, que presentan un perfil alto de ácidos grasos. Abdo et al. (2010) obtuvieron un porcentaje de extracto etéreo similar al de la presente investigación (12,80\%), aseverando que este contenido, se debe a la madurez fisiológica del animal.

La proteína, se considera el ingrediente más importante para las dietas en la nutrición animal. El contenido proteico hallado (Tabla 3) fue similar al reportado por Cuenca et al. (2013), quienes encontraron valores de 56,00\% y quienes, además, afirman que una harina de residuos pesqueros, con rango de proteína entre 50 y $55 \%$, es eficiente para la alimentación animal. Otras investigaciones reportan valores inferiores de proteína en harinas de vísceras de pescado $(48,00 \%)$, debido a la desnaturalización de la proteína, como consecuencia de las altas temperaturas, durante el proceso de elaboración (Córdoba-Murueta \& García- Carreño, 2002). Para la obtención de la HVP, se procuró no superar los $45-50^{\circ} \mathrm{C}$, para evitar una desestabilización de las estructuras proteicas, las cuales, son sensibles al calor, ya que un aumento de la temperatura acelera la transformación molecular, alterando los puentes de hidrógeno y enlaces no covalentes, que inducen a un deterioro y pérdida de la estructura terciaria de las proteínas (Benítez et al. 2008).

El contenido de cenizas presentó variaciones entre el 15 y 30\%, debido, probablemente, a la composición de las vísceras, ya que en ellas se pueden encontrar residuos de estructuras óseas, procedentes de los esqueletos y las cabezas. 
Tabla 3. Composición nutricional y perfil de ácidos grasos de la HVP elaborada.

\begin{tabular}{|c|c|c|c|c|c|c|c|}
\hline \multirow{2}{*}{$\begin{array}{c}\text { Harina de } \\
\text { vísceras de } \\
\text { pescado } \\
(\mathrm{HVP})\end{array}$} & $\begin{array}{c}\text { Extracto } \\
\text { etéreo } \mathrm{g} / 100 \mathrm{~g}\end{array}$ & $\begin{array}{l}\text { Humedad } \\
\mathrm{g} / 100 \mathrm{~g}\end{array}$ & $\begin{array}{l}\text { Proteína } \\
\mathrm{g} / 100 \mathrm{~g}\end{array}$ & $\begin{array}{l}\text { Cenizas } \\
\mathrm{g} / 100 \mathrm{~g}\end{array}$ & $\begin{array}{c}\mathrm{ELN}^{1} \\
\mathrm{~g} / 100 \mathrm{~g}\end{array}$ & $\begin{array}{l}\text { Fibra } \\
\text { g/100g }\end{array}$ & $\begin{array}{l}\text { Valor energético } \\
\text { Kcal/100g }\end{array}$ \\
\hline & 13,10 & 5,59 & 54,02 & 26,83 & 0,44 & 1,03 & 335,81 \\
\hline \multicolumn{8}{|c|}{ Perfil de ácidos grasos, $\%$} \\
\hline \multicolumn{4}{|c|}{ Grasa insaturada } & \multicolumn{4}{|c|}{28,50} \\
\hline \multicolumn{4}{|c|}{ Grasa saturada } & \multicolumn{4}{|c|}{8,04} \\
\hline \multicolumn{4}{|c|}{ Grasa monoinsaturada } & \multicolumn{4}{|c|}{12,87} \\
\hline \multicolumn{4}{|c|}{ Grasa poliinsaturada } & \multicolumn{4}{|c|}{15,62} \\
\hline \multicolumn{4}{|c|}{ Omega 3} & \multicolumn{4}{|c|}{11,77} \\
\hline \multicolumn{4}{|c|}{ Omega 6} & \multicolumn{4}{|c|}{7,59} \\
\hline \multicolumn{4}{|c|}{ Omega 9} & \multicolumn{4}{|c|}{4,66} \\
\hline \multicolumn{4}{|c|}{ Eicosapentaenoico (EPA) } & \multicolumn{4}{|c|}{3,09} \\
\hline \multicolumn{4}{|c|}{ Docosapentaenóico (DPA) } & \multicolumn{4}{|c|}{1,61} \\
\hline \multicolumn{4}{|c|}{ Docosahexaenoico (DHA) } & \multicolumn{4}{|c|}{4,51} \\
\hline
\end{tabular}

${ }^{1}$ ELN (Extracto libre de nitrógeno) almidones y azúcares presentes en la muestra, se obtienen cuantitativamente por diferencia.

Valores promedio de tres repeticiones $(\mathrm{n}=3)$.

El contenido de fibra cruda, obtenido en la HVP, fue muy bajo, normal en las materias primas de origen animal. Por otro lado, la HVP presentó un aporte significativo del valor energético (335kcal $/ 100 \mathrm{~g})$, similar al valor de energía bruta hallada en harina de pescado peruana $(395 \mathrm{kcal} / 100 \mathrm{~g})$, presentado por Gutiérrez et al. (2009), haciendo de la HVP un insumo alimenticio importante, por su aporte lipídico y proteico.

$\mathrm{El}$ análisis de los minerales ( $\mathrm{P}, \mathrm{Ca}$ y Fe) mostró valores similares a los encontrados por Izquierdo et al. (2001) en vísceras de pescado y por los hallados por Özden et al. (2010), en tres tipos de pescados comerciales, lo cual, permite concluir que la HVP es una fuente significativa de estos minerales, nutrientes de alta importancia para el metabolismo animal.

Se pudo comprobar que la HVP contiene, tanto aminoácidos esenciales como no esenciales. Como referencia, se tomaron los valores del contenido de aminoácidos reportados por la FAO (2015), para merluza y bacalao, encontrando valores superiores, a excepción de la alanina y el ácido glutámico. Andara et al. (2016) evaluaron el perfil de aminoácidos en tres dietas alimenticias para peces, hallando deficiencias en varios de los aminoácidos esenciales; varios de los aminoácidos reportados estuvieron por debajo de los encontrados en este estudio. Finalmente, Izquierdo et al. (2001) reportan, al igual que en esta investigación, deficiencia en metionina y triptófano.

La HVP presentó un perfil de ácidos grasos importante (Tabla 3). Osorio et al. (2014), en harina de cabezas, colas y esqueletos de tilapia, con relación a las grasas insaturadas, reportaron valores inferiores a los de esta investigación. En las vísceras, se concentra el mayor contenido de grasas, en relación con otras partes del cuerpo de diferentes animales (López et al. 2006). Sargent et al. (2002) reportan que los peces de agua dulce son clasificados como una buena fuente de ácidos grasos poliinsaturados, especialmente, los relacionados con el Omega 3, ya que poseen mayor capacidad de generar cadenas largas y quitar la saturación de los ácidos grasos de cadenas cortas. Con base al reporte del perfil lipídico hallado en la HVP, se afirma que es una opción ideal para la alimentación animal, ya que, especies como peces, aves y cerdos, requieren en su alimentación la inclusión de ácidos grasos insaturados, especialmente, el Omega 3 y el Omega 6 , para estimular el crecimiento y contribuir al sistema digestivo, cardiovascular e inmunológico (Orduña-Hernández et al. 2016; Valenzuela et al. 2012).

La determinación de metales pesados en la HVP reportó valores inferiores a 0,005ppm, para $\mathrm{Hg}, \mathrm{Cd}$ y $\mathrm{Pb}$, lo cual, se ajusta a lo estipulado en la Norma Técnica Colombiana NTC 1443 (ICONTEC, 2009), para productos de la pesca y acuicultura $(\mathrm{Cd}=0,1, \mathrm{Hg}=0,5$ y $\mathrm{Pb}=0,4 \mathrm{mg} / \mathrm{kg})$.

Los parámetros microbiológicos hallados para la HVP mostraron valores ajustados a lo permitido en la Norma Técnica Colombiana NTC 685/2004 (ICONTEC, 2004), lo cual, garantizó la utilización de dicha harina, para su valoración en la alimentación de los pollos.

Evaluación fisicoquímica de la HVP elaborada. La calidad de la HVP, se midió en función de su contenido lipídico; en la tabla 4, se aprecian los valores obtenidos. El índice de acidez fluctuó entre 1,35 y $2,89 \%$, respectivamente, para los días 5 y 30 de almacenamiento, valores que se enmarcan dentro de los criterios de calidad, para ser utilizadas en nutrición animal (FAO, 2015). 
Tabla 4. Análisis fisicoquímico de la HVP elaborada.

\begin{tabular}{|c|c|c|c|}
\hline & Día 5 & Día 30 & Valor de referencia \\
\hline Índice de acidez & $1,35 \%$ & $2,89 \%$ & $0,5-11 \%$ \\
\hline $\begin{array}{c}\text { Índice de peróxidos } \\
\text { Valor de anisidina }\end{array}$ & $1,66 \mathrm{meqO}_{2} / \mathrm{kg}$ & $2,22 \mathrm{meqO} / \mathrm{kg}$ & $<50 \mathrm{meqO}_{2} / \mathrm{kg}$ \\
\hline $\begin{array}{c}\text { Rancidez oxidativa } \\
\text { (TBARS) }\end{array}$ & $28,34 \mathrm{PAV}$ & $43,50 \mathrm{PAV}$ & $<52,00 \mathrm{PAV}$ \\
\hline $\begin{array}{c}\text { Bases volátiles } \\
\text { nitrogenadas totales (BVNT) }\end{array}$ & $23,45 \mathrm{mg} / \mathrm{kg}$ & $2,93 \mathrm{mg} / \mathrm{kg}$ & $8 \mathrm{mg} / \mathrm{kg}$ \\
\hline
\end{tabular}

Valores promedio de tres repeticiones $(\mathrm{n}=3)$.

Los reportes del índice de peróxidos, ácido tiobarbitúrico (TBA) y valor de anisidina permitieron cuantificar el índice de rancidez presente en la HVP elaborada. Cruz et al. (2000) indicaron que no hay efectos adversos, si el nivel de oxidación de este tipo de productos no excede los siguientes valores: peróxidos $<50 \mathrm{meqO}_{2} /$ $\mathrm{kg}$, TBA $<8 \mathrm{mg}$ de malondialdehido por $\mathrm{kg}$ y anisidina $<52$ PAV. Se puede concluir, que la HVP elaborada no presentó rancidez oxidativa, en ninguno de los tiempos de evaluación (días 5 y 30).

Con relación a los valores de BNVT, anota Vásquez et al. (2008), que las muestras provenientes de pescado no pueden superar los $20 \mathrm{mgN}_{2} / 100 \mathrm{~g}$, se consideran aceptables, si oscilan alrededor de los $30 \mathrm{mgN}_{2} / 100 \mathrm{~g}$, pero después de $40 \mathrm{mgN}_{2} / 100 \mathrm{~g}$, la mayoría de las autoridades reguladoras, lo considera un producto inaceptable. En esta investigación, se mostró que, a partir de los 30 días de almacenamiento, la HVP tiende a alcanzar valores superiores a los sugeridos, lo cual, demuestra que el producto va perdiendo frescura y calidad, ya que las BNVT son indicadores de alteración por causa de hidrólisis de las proteínas presentes en la harina (Cruz et al. 2000).

Se encontró que la HVP es digerible en cerca del $80 \%$, valor superior al reportado por Rosales-Conde \& Tang (1996), para harina de residuos de bocachico (68,79\%). Asimismo, Cuenca et al. (2013) reportaron que una digestibilidad de proteína igual o superior al 75\% resulta ser adecuada en la elaboración de dietas alimenticias para animales.
Evaluación in vivo de la HVP elaborada. El consumo de alimentos en los tres tratamientos con adición de HVP no reportó diferencias estadísticamente significativas $(\mathrm{p}<0,05)$, mientras que el tratamiento control (alimento comercial), sí presentó diferencias significativas con relación a los demás tratamientos $(\mathrm{p}<0,05)$, presentando un mayor consumo en peso (Tabla 5), lo cual, puede ser atribuido a que contenía una granulometría más adecuada para las aves que la del concentrado, elaborado a partir de la HVP. Los tres tratamientos $\mathrm{T}_{1}, \mathrm{~T}_{2}$ y $\mathrm{T}_{3}$ tuvieron un comportamiento similar, en cuanto a rangos de consumo por parte de los pollos.

La estimación de los residuos pesqueros mostró que, en la Ciénaga de Zapatosa, se dispone de gran material biológico procedente de las vísceras de los recursos ícticos de la misma. Dicho material biológico, debido a su contenido de proteína, que es de excelente calidad, con alto contenido de aminoácidos esenciales, presenta características nutricionales y funcionales, aptas para ser utilizado, en forma de harina, para la alimentación de pollos de engorde, favoreciendo, de esta forma, el desarrollo de las funciones metabólicas y fortaleciendo la formación de la estructura ósea de los mismos. Además, posee un perfil de ácidos grasos benéficos para la salud animal, tales como los ácidos grasos omega 3, 6 y 9 y ácidos grasos monoinsaturados y poliinsaturados, que se evidenció en los índices de desarrollo y crecimiento de los pollos manifestado en la ganancia de peso y la conversión alimenticia. Se detectó, que un aporte del 10\% de esta

Tabla 5. Rendimiento productivo de las aves de engorde alimentadas con HVP.

\begin{tabular}{|l|c|c|c|c|}
\hline \multicolumn{1}{|c|}{ Parámetros } & $\mathbf{T}_{\mathbf{1}} \mathbf{( 5 \% )}$ & $\left.\mathbf{T}_{\mathbf{2}} \mathbf{( 1 0} \mathbf{0}\right)$ & $\mathbf{T}_{\mathbf{3}} \mathbf{( 1 5 \% )}$ & $\mathbf{T}_{\mathbf{4}}$ (Control) \\
\hline Aves por tratamiento & 25 & 25 & 25 & 25 \\
\hline Peso inicial (g) & $57,62^{\mathrm{a}}$ & $60,46^{\mathrm{a}}$ & $58,30^{\mathrm{a}}$ & $59,90^{\mathrm{a}}$ \\
\hline Ganancia total de peso (g) & $1353,25^{\mathrm{a}}$ & $1426,75^{\mathrm{a}}$ & $1370,50^{\mathrm{a}}$ & $1215,75^{\mathrm{a}}$ \\
\hline Ganancia diaria de peso (g) & $54,13^{\mathrm{a}}$ & $57,07^{\mathrm{a}}$ & $54,82^{\mathrm{a}}$ & $48,63^{\mathrm{a}}$ \\
\hline Peso final (g) & $1.907^{\mathrm{a}}$ & $1.996^{\mathrm{a}}$ & $1.958^{\mathrm{a}}$ & $1.682^{\mathrm{a}}$ \\
\hline Consumo de alimento (g) & $2.543^{\mathrm{a}}$ & $2.376^{\mathrm{a}}$ & $2.487^{\mathrm{a}}$ & $2.745^{\mathrm{b}}$ \\
\hline Conversión alimenticia & $1,87^{\mathrm{a}}$ & $1,67^{\mathrm{a}}$ & $1,81^{\mathrm{a}}$ & $2,25^{\mathrm{b}}$ \\
\hline Índice de mortalidad (\%) & & 3 & \\
\hline
\end{tabular}

Medias en una misma fila que posean diferentes superíndices difieren significativamente $(\mathrm{p}<0,05)$. 
harina, incluida en la formulación de los concentrados, proporciona un desarrollo y crecimiento importante de las aves. Por lo anterior, se puede pensar en maximizar la producción aviar de la región y, además, ayudar a reducir las cargas contaminantes que este tipo de residuos generan en la Ciénaga de Zapatosa.

Conflicto de intereses: El manuscrito fue preparado y revisado con la participación de todos los autores, quienes declaramos que no existe conflicto de intereses que ponga en riesgo la validez de los resultados presentados. Financiación: Este estudio fue financiado por la Gobernación del Cesar dentro del marco del proyecto "Consolidación de las capacidades de ciencia, tecnología e innovación del sector agropecuario del departamento del Cesar" - componente acuícola y pesquero.

\section{REFERENCIAS}

1. ABDO, M.A.; RODRÍGUEZ-IBARRA, E.; HERNÁNDEZ, K.; GONZÁLEZ-RODRÍGUEZ, B.; MARTÍNEZRODRÍGUEZ, I.; GARCÍA-ORTEGA, A. 2010. Efecto de diferentes niveles de proteína y lípidos totales en la dieta sobre el crecimiento y supervivencia de juveniles de pargo lunarejo Lutjanis guttatus. Rev. Biol. Mar. Oceanog. 45(3):433-439.

https://doi.org/10.4067/S0718-19572010000300008

2. AL-MARZOOQUI, W.; AL-FARSI, M.A.; KADIM, I.T.; MAHGOUB, O.; GODDARD, J.S. 2010. The effect of feeding different levels of sardine fish silage on broiler performance, meat quality, and sensory characteristics under closed and open-sided housing systems. Asian Aust. J. Anim. Sci. 23(12):1614-1625.

3. ALKAHIR, S.M.; MUSHARAF, N.A.; HAMID, I.I.; ALKURDI, O.I. 2017. The effect of limiting feeding time by three and six hours per day during the starter period on broiler performance. Int. J. Livest. Prod. 8(8):125-130. https://doi.org/10.5897/IJLP2016.0329

4. AMERICAN OIL CHEMISTS' SOCIETY, AOCS. 2017. Official method Ce 1i-07. Champaign-Urbain, IL, USA. Disponible desde Internet en:

https://www.aocs.org/attain-lab-services/methods/ methods/search-results?method=111779 (con acceso 03/25/2019).

5. ANDARA, M.; ARIAS, J.; BELANDRIA, J.; BRIEVA, J.; GÓMEZ, W. 2016. Amino acid profile formulated diets for fish feed, using industrial waste processing crustaceans. Rev. Tecncien. Uru. 10:59-66.

6. ASSOCIATION OF OFFICIAL ANALYTICAL CHEMISTS AOAC. 2006. Official Methods of Analysis. 18th Edition, Gaithersburgs, MD.
7. AUTORIDAD NACIONAL DE ACUICULTURA Y PESCA, AUNAP. 2014. Plan Nacional para el Desarrollo de la Acuicultura Sostenible en Colombia. PlaNDAS. Ministerio de Agricultura y Desarrollo Rural - MADR, Bogotá, Colombia. Disponible desde Internet en: http://www.aunap.gov.co (con acceso 03/09/2019).

8. AUTORIDAD NACIONAL DE ACUICULTURA Y PESCA, AUNAP. 2018. Boletín de Prensa. En el país, consumo de pescado por persona supera los ocho kilos al año. Ministerio de Agricultura y Desarrollo Rural - MADR. Bogotá, Colombia. Disponible desde Internet en: https://aunap.gov.co/attachments/article/140/401.\%20 $\mathrm{Se} \% 20$ acerca $\% 201 \mathrm{a} \% 20$ Semana $\% 20$ Mayor.pdf (con acceso $21 / 11 / 2020)$.

9. BENÍTEZ, R.; IBARZ, A.; PAGAN, J. 2008. Protein hydrolyzates: processes and applications. Acta Bioquim. Clin. Latin. 42(2):227-236.

10. CÓRDOBA-MURUETA, J.H.; GARCÍA-CARREÑO, F.L. 2002. Nutritive value of squid and hydrolysed protein supplement in shrimp feed. Aquaculture. 210(1-4):371-384. https://doi.org/10.1016/S044-8486(02)00011-X

11. CRUZ S., L.E.; RICQUE M., D.; NIETO L., M.; TAPIA S., M. 2000. Revisión sobre calidad de harinas y aceites de pescado para la nutrición del camarón. En: Avances en Nutrición Acuícola IV. Memorias del IV Simposium Internacional de Nutrición Acuícola. La Paz, B.C.S., México, p.298-326.

12. CUENCA S., C.A.; ÁLVAREZ G., C.A.; ORTIZ-GALINDO, J.I.; GUERRERO-ZÁRATE, T.; PEREIRA-GARCÍA, M.A.; HERNÁNDEZ-GÓMEZ, R.E.; NOLASCOSORIA, H. 2013. Digestibilidad in vitro de ingredientes proteínicos en la mojarra castarrica (Cichlasoma urophthalmus). Univ. Cienc. Trop. Hum. 29(3):363-275.

13. DAVID-RUALES, C.A.; TORRES-TORO, C.; HIMCAPIÉÁVILA, S.; LONDOÑO-LONDOÑO, J. 2014. Aprovechamiento de residuos de trucha arco iris Oncorbynchus mykiss: uso de tecnologías limpias para la extracción de aceite. Orinoquia. 18(2):294-299.

14. EMBUS-CLAVIJO, N. 2016. Elaboración de harina de vísceras de pescado (HVP) mojarra roja (Oreochromis sp) y determinación de su composición nutricional, como fuente alimenticia para animales en Garzón (Huila). Rev. Invest. Agroemp. 2:26-34. https://doi.org/10.23850/25004468.831

15. FONSECA, C.; MANTOVANI F., L.; D’AVILA, L.; EDWIGES, T. 2020. Influence of different waste compositions from tilapia fish on methane production. J. Cleaner Prod. 265:121795.

https://doi.org/10.1016/j.clepro.2020.121795 
16. FOOD AND AGRICULTURE ORGANIZATION OF THE UNITED NATIONS, FAO. 2015. Departamento de pesca y acuicultura. Control de calidad de insumos y dietas acuícolas. Santiago, Chile. Disponible desde Internet en: https://www.fao.org/3/a-i5555s.pdf (con acceso 05/03/2019).

17. GARCÉS, Y.; PEREA, C.; VALENCIA, N.; HOYOS, J.; GÓMEZ, J. 2015. Nutritional effect of the chemical silage of fish by-products in broiler (Gallus domesticus) feeding. Cuban J. Agric. Sci. 49(4):503-508.

18. GOROSTEGUI, H.; MUFARI, J.; ORRABALIS, C.; GUZMÁN, C.; CALANDRI, E. 2012. Cuantificación de aminoácidos totales en harinas residuales de la extracción de aceite de Copernicia alba morong. II Jornada de investigación en ingeniería del NEA y países limítrofes. Universidad Tecnológica Nacional, Facultad Regional Resistencia, Chaco, Argentina. 5p.

19. GUTIÉRREZ, F.W.; ZALDÍVAR, J.; CONTRERAS, G. 2009. Coeficiente de digestibilidad aparente de harina de pescado peruana y maíz amarillo duro para Colossoma macropomum (Actinopterygii characidae). Rev. Per. Biol. 15(2):111-115. https://doi.org/10.15381/rph.v15i2.1735

20. HERRERA A., F.C.; SANTOS B., J.A. 2005. Prevalencia de Salmonella spp en pescado fresco expendido en Pamplona (Norte de Santander). Bistua. Rev. Fac. Cienc. Basic. $3(2): 34-42$.

21. HODAR, A.R.; VASAVA, R.J.; MAHAVADIYA, D.R.; JOSHI, N.H. 2020. Fish meal and fish oil replacement for aqua feed formulation by using alternative sources: a review. J. Exp. Zool. India. 23(1):13-21.

22. INSTITUTO COLOMBIANO AGROPECUARIO, ICA. 2014. Directivas técnicas de alimentos para animales y sales mineralizadas. Ministerio de Agricultura y Desarrollo Rural - MADR, Bogotá, Colombia. Disponible desde Internet en: http://www.ica.gov.co (con acceso 07/08/2018).

23. INSTITUTO COLOMBIANO DE NORMAS TÉCNICAS Y CERTIFICACIÓN, ICONTEC. 2004. NTC - 685. Alimentos para animales. Harinas de subproductos de origen animal. Bogotá, Colombia. 6p. Disponible desde Internet en: https:/ / docplayer.es / 93136861 -Norma-tecnicacolombiana-685.html (con acceso 24/02/2019).

24. INSTITUTO COLOMBIANO DE NORMAS TÉCNICAS Y CERTIFICACIÓN, ICONTEC. 2009. NTC - 1443. Productos de la pesca y la acuicultura. Pescado entero, medallones y trozos, refrigerados o congelados. Bogotá, Colombia. 13p. Disponible desde Internet en:
https://www.academia.edu/18831518/NTC_1443_ Productos_de_La_Pesca_y_Acuicultura (con acceso 20/02/2019).

25. INSTITUTO DE HIDROLOGÍA, METEOROLOGÍA Y ESTUDIOS AMBIENTALES, IDEAM. 2012. Establecimiento de la línea base ambiental del complejo cenagoso de Zapatosa. Ministerio de Ambiente, Vivienda y desarrollo. Bogotá, Colombia. 40p. Disponible desde Internet en:

http://www.corpocesar.gov.co/czapatosa.html (con acceso 18/01/2019).

26. IZQUIERDO, P.; TORRES, G.; ALLARA, M.; MÁRQUEZ, E.; BARBOZA, Y.; SÁNCHEZ, E. 2001. Análisis proximal, contenido de aminoácidos esenciales y relación calcio/ fósforo en algunas especies de pescado. Rev. Cient. FVCLUZ. 11(2):95-100.

27. LÓPEZ, L.M.; DURAZO, E.; RODRÍGUEZ-GÓMEZ, A.; TRUE, C.D.; VIANA, M.T. 2006. Composición proximal y perfil de ácidos grasos de juveniles silvestres y cultivados de Totoaba macdonaldi. Cienc. Mar. 32(2):303-309.

28. MALONE, T.C.; NEWTON, A. 2020. The globalization of cultural eutrophication in the coastal ocean: causes and consequences. Front. Mar. Sci. 7:670. https://doi.org/10.3389/fmars.2020.00670

29. MINISTERIO DE SALUD DE COLOMBIA, MINSALUD. 1991. Resolución No. 4124 de 1991. Bogotá, Colombia. Disponible desde Internet en: https://www.minsalud.gov.co/sites/rid/Lists / BibliotecaDigital/RIDE/DE/DIJ/Resolucion\%204124de-1991.pdf (con acceso 02/03/2019).

30. ORDUÑA-HERNÁNDEZ, H.M.; SALINAS-CHAVIRA, J.; MONTAÑO-GÓMEZ, M.F.; INFANTE-RODRIGUEZ, F; MANRIQUEZ-NUÑEZ, O.M.; VÁSQUEZSAUCEDO, M.; YADO-PUENTE, R. 2016. Efecto de la sustitución de grasa de fritura por aceite vegetal y concentración energética en dietas para la producción de pollos de engorde. CienciaUAT. 10(2):44-51.

31. OSORIO, A.; WILLS, A.; MUÑOZ, A.P. 2014. Caracterización de coproductos de la industria del fileteado de tilapia roja (Oreochromis niloticus) en Colombia. Rev. Fac. Med. Vet. Zoot. 60(3):182-195.

32. OSORIO-CARMONA, E.; GIRALDO-CARMONA, J.; NARVÁEZ-SOLARTE, W. 2012. Metodologías para determinar la digestibilidad de los alimentos utilizados. Vet. Zootec. 6(1):87-97.

33. ÖZDEN, Ö.; ERKAN, N.; ULUSOY, S. 2010. Determination of mineral composition in three commercial fish species 
(Solea solea, Mullus surmuletus, and Merlangius merlangus). Environ. Monit. Assess. 170:353-363.

https://doi.org/10.1007/s10661-009-1238-5

34. PEREA-ROMÁN, C.; GARCÉS-CAICEDO, Y.J.; MUÑOZARBOLEDA, L.S.; HOYOS-CONCHA, J.L.; GOMEZPEÑARANDA, J.A. 2018. Valoración económica del uso de ensilaje de residuos piscícolas en la alimentación de Oreochromis spp. Rev. Bio. Agrop. Agroind. 16(1):43-51. https://doi.org/10.18684/bsaa.v16n1.623

35. PINZÓN N., L.M.; SÁNCHEZ J., C.A.; MUÑOZ H., J.A.; HERNÁNDEZ S., H.M. 2016. Aprovechamiento de las vísceras de pescado como fuente de energía para minimizar el problema de contaminación ambiental del sector piscícola. Rev. Inv. Agrar. Amb. 7(2):1-6. https://doi.org/10.22490/21456453.1623

36. RAMÍREZ, J.; IBARRA, J.; ROMERO, F.; ROSAS, P.; ULLOA, J.; MATSUMOTO, K.; VALLEJO, B.; MAZORRA, M. 2013. Preparation of Biological fish silage and its effect on the performance and meat quality characteristics of quails (Coturnix coturnix japonica). Braz. Arch. Biol. Technol. 56(6):1002-1010. https://doi.org/10.1590/S1516-89132013000600016

37. RAMÍREZ U., J.A.; MORA U., M.G.; VÁQUIRO H., H.A.; SOLANILLA D., J.F. 2016. Hidrólisis enzimática de vísceras de pescado utilizando pepsina y pancreatina. Agron. Colomb. 34(Supl.1):1013-1015.

https://doi.org/10.15446/agron.colomb.v34n1supl.58030

38. ROSALES-CONDE, J.M.; TANG, T. 1996. Composición química y digestibilidad de insumos alimenticios de la zona de Ucayali. Folia Amazónica. 8(2):13-27. https://doi.org/10.24841/ fa.v8i2.318

39. ROSTAGNO, H.S. 2011. Tablas brasileñas para aves y cerdos. Composición de alimentos y requerimientos nutricionales. 3ra. Edición. Universidad Federal de Viçosa. Brasil. 259p.

40. RUIZ, M.; MUÑOZ, L.; LETERME, P. 2005. Desarrollo de una metodología in vitro para estimar la tasa de fermentación de los forrajes en el intestino grueso del cerdo. Acta. Agron. 54(4):47-54.

41. SARGENT, J.R.; TOCHER, D.R.; BELL, G. 2002. The lipids. In: Halver J.E.; Hardy R.W. (eds) (Third Edition). Elsevier Science. Academic Press. p.187-257.
42. SERVICIO ESTADÍSTICO PESQUERO COLOMBIANO, SEPEC. 2018. Informe gráficas capturas desemb arcadas. Bogotá, Colombia. Disponible desde Internet en: https:/ /www.sepe.aunap.gov.co/informesAvanzados/ Index2 (con acceso 18/01/2019).

43. SPANOPOULOS-HERNÁNDEZ, M.; PONCE-PALAFOX, J.T.; BARBA-QUINTERO, G.; RUELAS-INZUNZA, J.R.; TIZNADO-CONTRERAS, M.R.; HERNÁNDEZGONZÁLEZ, C.; SHIRAI, K. 2010. Producción de ensilado biológicos a partir de desechos de pescado, del ahumado de atún aleta amarilla (Thunnus albacares) y del fileteado de tilapia (Oreochromis sp.), para la alimentación de especies acuícolas. Rev. Mex. Ing. Quim. 9(2):167-178.

44. VALENZUELA, A.; SANHUEZA, J.; DE LA BARRA, F. 2012. El aceite de pescado; ayer un desecho industrial, hoy un producto de alto valor nutricional. Rev. Chil. Nutr. 39(2):201-209.

https://doi.org/10.4067/S0717-75182012000200009

45. VALENZUELA, C.; CARVALLO, F.; MORALES, M.; REYES, P. 2015. Efecto del uso de ensilado seco de salmón en dietas de pollos broiler sobre parámetros productivos y calidad sensorial de la carne. Archivos Medicina Veterinaria. 47(1):53-59.

https://doi.org/10.4067/S0301-732X2015000100010

46. VÁSQUEZ, J.A.; DOCASAL. S.F.; PRIETO, M.A.; GONZÁLEZ, M.P.; MURADO, M.A. 2008. Growth and metabolic features of lactic acid bacteria in media with hydrolysed fish viscera. An approach to biosilage of fishing by-product. Bioresour. Technol. 99(14):6246-6257. https://doi.org/10.1016/j.biortech.2007.12.006

47. VÁSQUEZ-TORRES, W.; YOSSA, M.I.; GUTIÉRREZESPINOSA, M.C. 2013. Digestibilidad aparente de ingredientes de origen vegetal y animal en la cachama. Pesq. Agropec. Bras. 48(8):920-927. https://doi.org/10.1590/S0100-204X2013000800016

48. VILORIA, J. 2008. Economía extractiva y pobreza en la Cíenaga de Zapatosa. Documentos de Trabajo sobre Economía Regional. 3:7-63.

49. YING, 1.; PEI, X.; YAN, J.; LIU, D.; ZHANG, H.; YU, B.; LI, N.; YANG, D. 2019. Prevalence of foodborne pathogens isolated from retail freshwater fish and shellfish in China. Food Control. 99:131-136. https://doi.org/10.1016/j.foodcont.2018.12.024 